\title{
Cyclical Fluctuations in Brazil's Real Exchange Rate: the Role of Domestic and External Factors (1988-95)*
}

\author{
Pierre-Richard Agénor** \\ Alexander W. Hoffmaister*** \\ Carlos Medeiros***
}

Summary: 1. Introduction; 2. Analytical background; 3. Empirical methodology; 4. Estimation and variance decomposition; 5. Shock to foreign interest rates; 6 . Summary and conclusions.

Key words: capital flows; real exchange rate; external shocks. JEL codes: E44; F32 and F34.

This paper examines the behavior of capital inflows and the real exchange rate in Brazil during the period 1988-95. The first part describes the analytical framework. The second part estimates (using monthly data) a near-VAR linking capital flows, changes in domestic and foreign nominal interest rates, changes in the expected depreciation rate, the government spending-output ratio, and changes in the real exchange rate. Generalized variance decompositions indicate that world interest rate shocks explain only a fraction of mediumterm fluctuations in capital flows, whereas fluctuations in the real exchange rate are driven mostly by its own innovations. Generalized impulse response functions show that a reduction in the world interest rate leads on impact to a fall in domestic interest rates, a reduction in the rate of nominal exchange rate appreciation, a capital inflow, and a depreciation of the real exchange rate.

O artigo analisa o comportamento do fluxo de capital e da taxa real de câmbio no Brasil durante o período 1988-95. A primeira parte descreve o modelo analítico. A segunda estima, usando dados mensais, um near-VAR que relaciona fluxo de capital, mudanças nas taxas de juros nominais domésticas e internacionais, mudanças na taxa de depreciação esperada, relação gastos do governo/PIB e mudanças na taxa de câmbio real. As decomposições das variâncias indicam que choques na taxa de juros internacionais explicam apenas uma fração das flutuações de médio prazo nos fluxos de capital, enquanto flutuações na taxa de câmbio real são influenciadas principalmente por inovações nela mesma. As funções impulso resposta mostram que reduções na taxa de juros internacional causam os seguintes impactos:

${ }^{*}$ This paper was received in Jan. and approved in Sept. 2001. The authors would like to thank, without implication, Trevor Alleyne, Eliana Cardoso, Márcio Garcia, Ilan Goldfajn, Lorenzo Pérez, Peter Wickham, Rogerio Zandamela, and an anonymous referee for helpful discussions and comments, the Brazilian authorities for providing some of the data used here, and Brooks Calvo and Nihal Bayraktar for excellent research assistance. The views expressed in this paper do not necessarily represent those of the bank or of the fund.

** International Monetary Fund.

*** World Bank. 
quedas na taxa de juros doméstica, reduções na apreciação da taxa nominal de câmbio, aumentos no fluxo capital e depreciação na taxa real de câmbio.

\section{Introduction}

The potentially adverse effect of large capital inflows on domestic inflation and the real exchange rate (as well as, ultimately, the current account) has been one of the main concerns of policymakers in developing countries and transition economies in recent years. As argued in a number of recent studies, the composition of capital flows, the degree of price stickiness and the degree of nominal exchange rate flexibility have been important factors in determining the effect of capital inflows on domestic macroeconomic outcomes. In countries where capital inflows have taken the form of portfolio investment (as opposed to foreign direct investment), they have often been associated with an increase in consumption rather than investment. In turn, the increase in consumption has often taken the form of a large increase in expenditure on nontradable goods, thereby leading to a real appreciation. In countries where a fixed (or predetermined) exchange rate has been used as a nominal anchor to reduce inflation (as was the case in Argentina, for instance), inertial factors have led to an upward pressure on prices of nontradable goods and to a real appreciation. ${ }^{1}$

This paper provides a quantitative analysis of the effects of domestic and external factors on capital inflows and short-run fluctuations in Brazil's real exchange rate over the period 1988-95. The importance of assessing these effects is well illustrated in the recent literature on capital inflows (Agénor \& Hoffmaister, 1998). ${ }^{2}$ Brazil's experience in the early 1990s provides an interesting case to study the effects of capital inflows and macroeconomic policy response on the real exchange rate. ${ }^{3}$ Large net outflows were recorded in the 1980s, reflecting both the uncertainty associated with the "stop and go" approach to stabilization and the restrictions on access to world capital markets

\footnotetext{
${ }^{1}$ See Agénor \& Hoffmaister (1998) and Calvo, Leiderman \& Reinhart (1996) for a discussion of these issues.

${ }^{2}$ In addition, we are not aware of any other study focusing on monthly observations to address the issue of external shocks on capital flows and the real exchange rate in a VAR framework.

${ }^{3}$ See Cardoso (1997) and Cardoso \& Goldfajn (1998) for a detailed overview of macroeconomic policy (and responses to capital inflows) in Brazil in recent years.
} 
that the country faced in the aftermath of the debt crisis. In the early 1990s (as shown in figure 1) Brazil recorded a surge in inflows, reflecting partly the fact that interest rate differentials became highly favorable to domestic currency denominated assets, and partly changes in the institutional environment. ${ }^{4}$ Immediately after the introduction of the Real Plan in mid-1994, capital inflows increased sharply. They fell substantially in early 1995, in the aftermath of the Mexican peso crisis. Capital inflows - in the form of both portfolio investment and foreign direct investment - resumed in the second half of 1995, as confidence in the exchange rate band system increased. Gross international reserves rose to record levels as of end-1995. In part because this increase posed problems for monetary management, the authorities took measures to limit capital inflows on several occasions during the past four years, as summarized in table 1, with a limited degree of effectiveness (Garcia \& Barcinski, 1996).

The magnitude of the inflows recorded by Brazil (as well as several other developing countries) in recent years and the fears that they could be subject to abrupt reversal have raised concerns among policymakers regarding their capacity to contain monetary and credit expansion, to control inflation, and, most importantly, to avoid a real exchange rate appreciation and a deterioration in the external current account. In Brazil, as well as in various other countries, a deterioration in competitiveness has been viewed as having the undesirable effect of raising questions about the credibility and sustainability of the exchange rate regime, and possibly leading to bouts of exchange market pressures. ${ }^{5}$

The behavior of the real exchange rate during the recent inflows episode is illustrated in figure 1. In addition to potential effects of capital flows, changes in exchange rate policy have also been important. For most of the second half of the 1980s, Brazil had a relatively flexible exchange rate policy; but under the heterodox stabilization programs of the late 1980s, the domestic currency

\footnotetext{
${ }^{4}$ Restrictions on access of foreign institutional investors to domestic stock markets were lifted in 1991, and the limits on portfolio composition and the minimum holding period for investments were abolished. At the same time, the authorities approved the issuance of debentures convertible into stocks in domestic enterprises. In mid-1992, foreign financial institutions (mutual funds, investment companies, and institutional investors) were authorized to operate in the options and futures markets for securities, foreign exchange, and interest rates.

${ }^{5}$ As it turned out, Brazil faced a severe exchange crisis in January 1999. These events are still unfolding at the time of this writing.
} 
Figure 1

Brazil: private capital inflows, interest rate differential and the real exchange rate, 1988-95

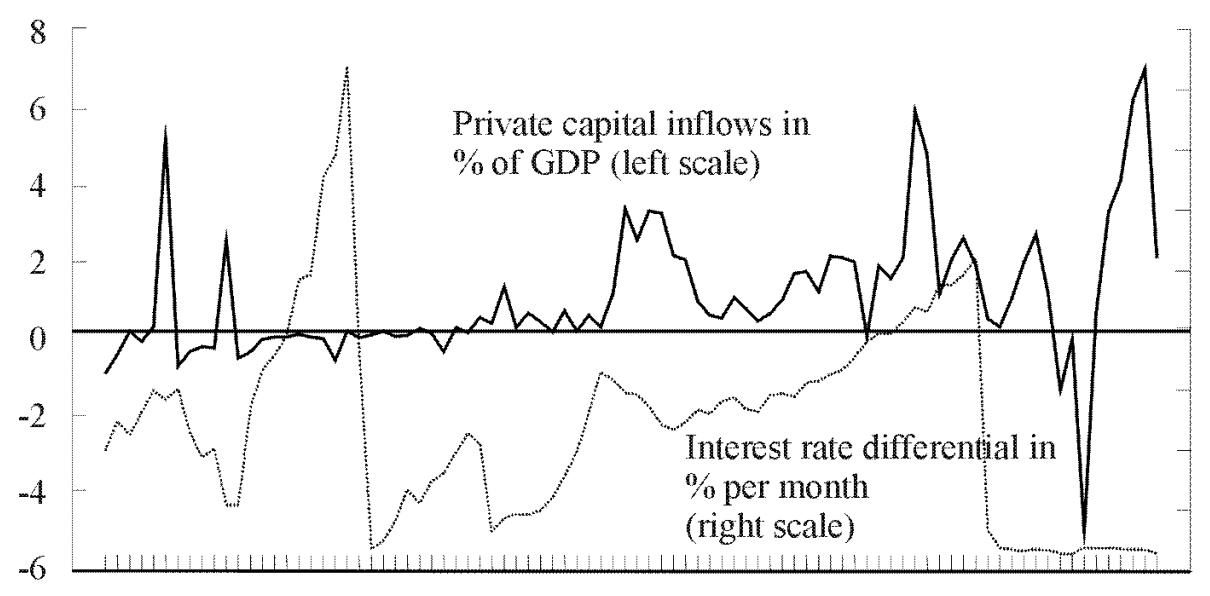

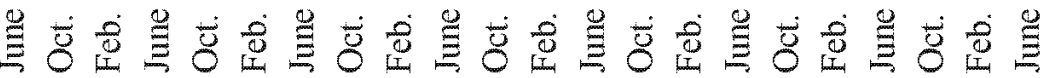

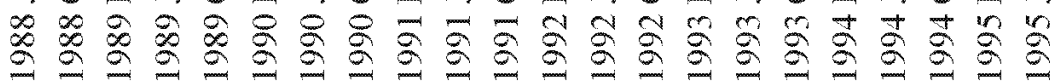

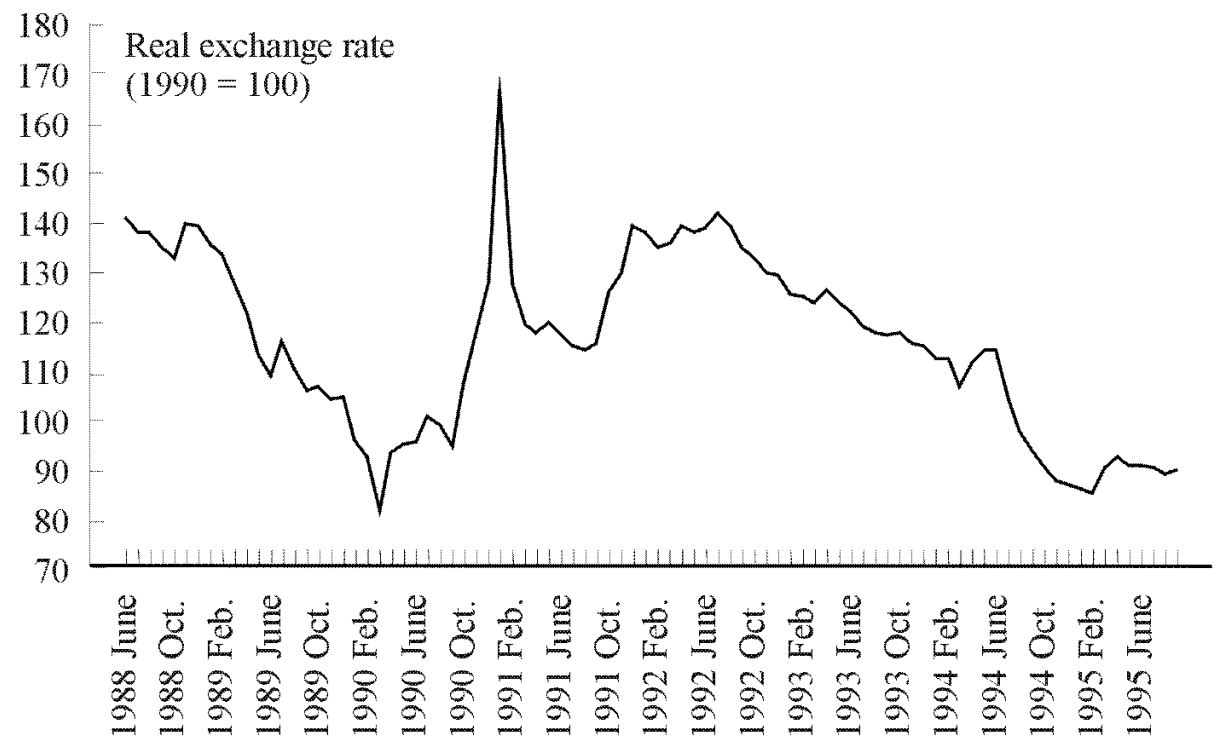

Note: The interest rate differential is measured as the difference between the overnight interest rate in Brazil minus the 90-day U.S. T-bill rate and the ex post, one-month ahead rate of depreciation of the domestic currency-U.S. dollar exchange rate. In the lower panel, a rise is a depreciation. 


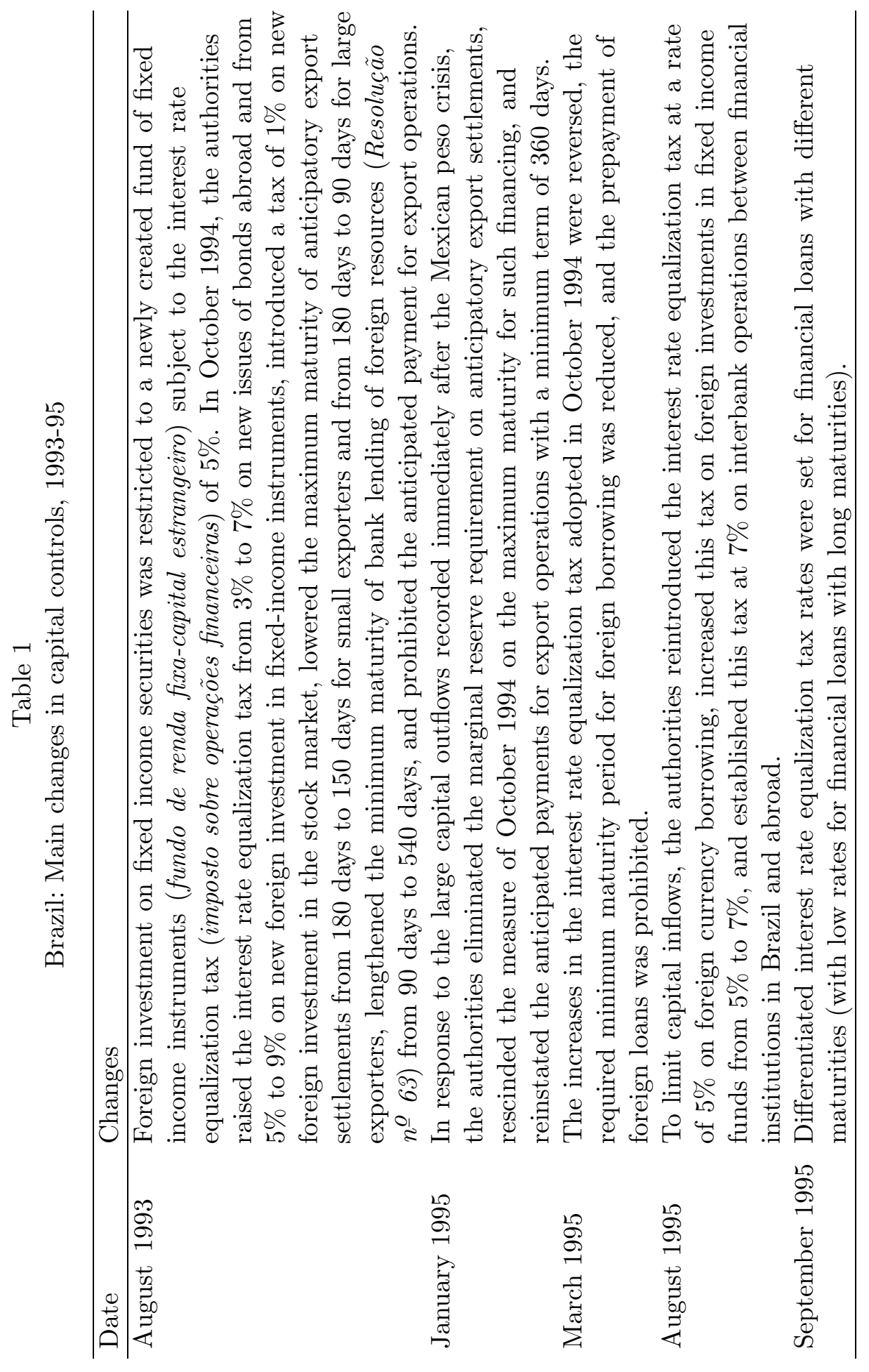

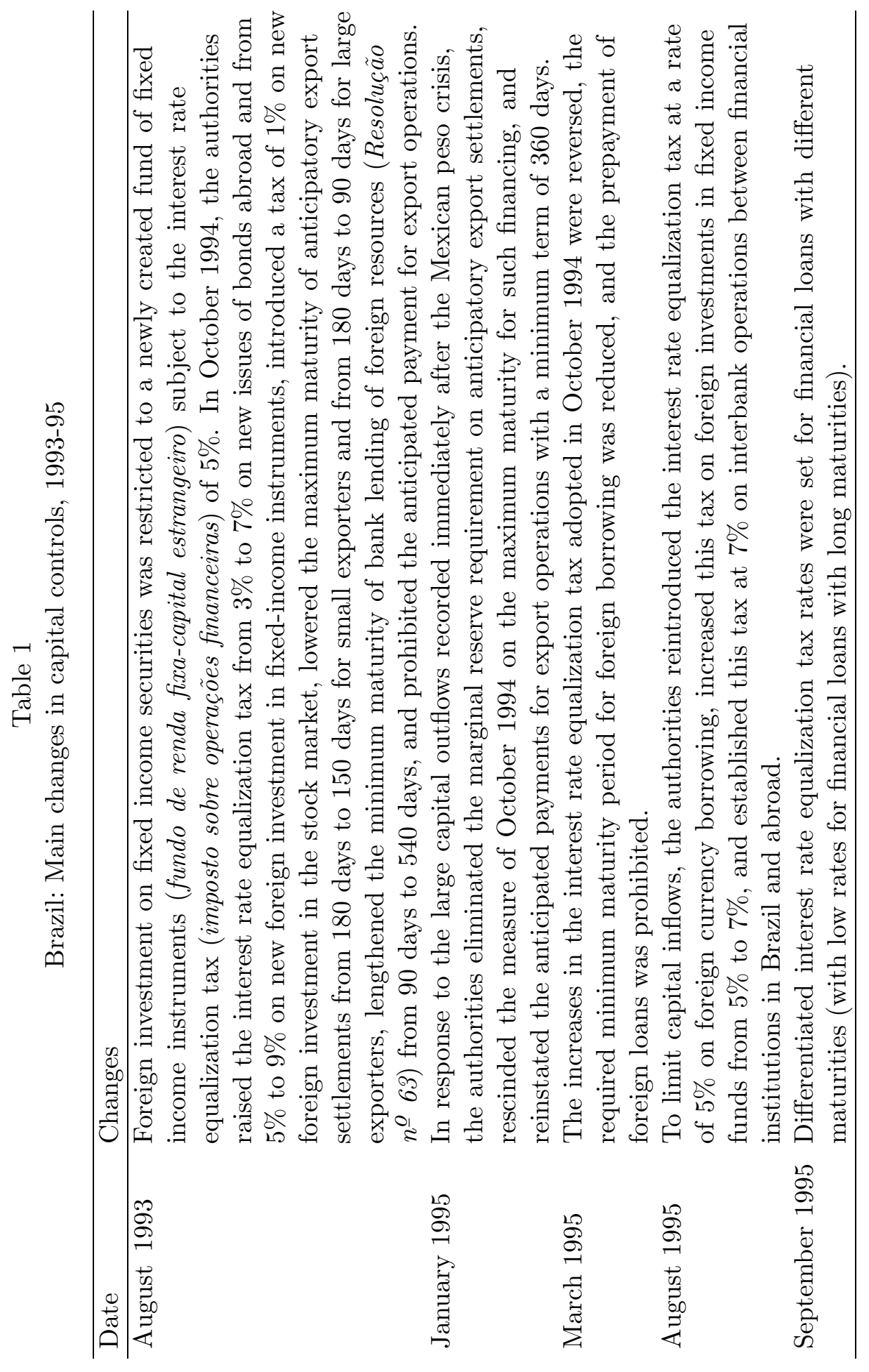


was temporarily fixed in terms of the US dollar or adjusted by less than past inflation. These policies brought about a marked appreciation of the exchange rate, as illustrated in figure 1. After a devaluation of the domestic currency in late 1991, exchange rate management aimed at maintaining the exchange rate stable in real terms. In the context of the Real Plan, the authorities introduced on July 1, 1994 a new currency, the real, with a floating exchange rate subject to a floor of $\mathrm{R} \$ 1$ per US dollar. The real appreciated rapidly visà-vis the US dollar, both in nominal and real terms. Following the Mexican peso crisis, the authorities introduced exchange rate bands in early March 1995, and maintained that policy until January $1999 .^{6}$

Section 2 provides the analytical background for our analysis of the effects of external shocks (namely, a shock to nominal world interest rates) on capital flows and the real exchange rate. Section 3 describes the methodology. Section 4 presents estimates of a VAR model linking capital inflows, domestic and foreign nominal interest rates, expected depreciation, government spending, and the rate of change of the real exchange rate. Generalized variance decompositions are used to assess the relative importance of external factors in explaining fluctuations in capital flows and the real exchange rate. In Section 5 the effects of a shock to foreign nominal interest rates are assessed using generalized impulse response functions. The concluding section summarizes the main results of the paper and discusses the policy implications of the analysis.

\section{Analytical Background}

A useful background framework for our empirical analysis of the effects of external shocks on capital flows and the real exchange rate in Brazil are the intertemporal optimizing models developed by Agénor (1998), whose model assumes flexible prices, and Kollman (1997), whose model introduces (more realistically) nominal price rigidities. Both models, however, help to emphasize that even in circumstances in which changes in world nominal interest

\footnotetext{
${ }^{6}$ The initial band was set at R\$0.86-R\$0.90 per US dollar and was to be effective through May 1, 1995. However, because of the uncertainty about the exchange rate policy that would be adopted after that date, severe exchange market pressures developed. On March 10, 1995 the authorities set the band at $R \$ 0.88-R \$ 0.93$ per US dollar and announced that it would be effective for an indefinite period. The exchange rate band subsequently was modified on June 22, 1995 to R\$0.91-R\$0.99 per US dollar, on January 30, 1996 to $R \$ 0.97-R \$ 1.06$ per US dollar, and on February 18, 1997 to R\$1.05-R\$1.14 per US dollar.
} 
rates provide an "impulse" effect on capital inflows, feedback effects on capital movements tend to occur through changes in domestic rates of return which are determined, together with the real exchange rate itself, by macroeconomic equilibrium conditions. Accounting for these interactions is essential to understand the dynamics associated with external shocks. In addition, the models also highlight the importance of distinguishing between the shortand long-term dynamics of capital flows, asset accumulation, and the real exchange rate in order to assess the effects of macroeconomic shocks to world interest rates. Impact movements in domestic nominal interest rates and the real exchange rate will typically lead to subsequent portfolio reallocations and shifts in production or consumption patterns, which may generate correcting movements in relative prices.

Agénor (1998), in particular, analyzed the macroeconomic effects of both permanent and temporary reductions in world interest rates. An essential feature of his model is the focus on individual (as opposed to country) risk, captured through the assumption that domestic private borrowers face an upward-sloping supply curve of funds on world capital markets - an assumption that leads to a setting in which capital is imperfectly mobile internationally. Agénor's analysis showed that a permanent reduction in the world interest rate leads to a steady-state reduction in the economy's net stock of foreign assets and a depreciation of the real exchange rate if the economy is initially a net creditor. The reduction in the world interest rate leads to a fall in holdings of foreign assets and reduced interest income in the steady state. To ensure long-run equilibrium of the current account, the economy must reduce its trade deficit. This, in turn, requires a reduction in private consumption, with the lower demand for nontraded goods leading to a depreciation of the real exchange rate. The real depreciation raises output of traded goods and reinforces the effect of the reduction in consumption on the trade balance. On impact, the real exchange rate may either appreciate or depreciate. The reason is the existence of offsetting wealth and intertemporal effects on consumption: on the one hand, the reduction in the world interest rate lowers (current and expected) income, which tends to reduce private spending today; on the other hand, it lowers the cost of borrowing, which tends to raise consumption today.

If the economy is initially a net debtor, the long-run effects are qualitatively similar to those described above: consumption falls, the real exchange rate 
depreciates, and external debt increases. On impact, however, the ambiguity obtained previously disappears: a reduction in the world nominal interest rate always increases private consumption and appreciates the real exchange rate. The reason is that now wealth and intertemporal effects operate in the same direction: a reduction in the cost of foreign borrowing not only encourages agents to save less today, but it also lowers the external debt burden - thereby generating a positive wealth effect.

From an empirical point of view, the above analysis emphasizes two points. First, for the effects of world interest rates on capital flows, the real exchange rate and domestic rates of return must be accounted for jointly. Second, the short-term effects of temporary shocks to world interest rates on the real exchange rate are, in general, ambiguous and depend on the net asset position of the economy and the degree of intertemporal substitution.

In what follows we use a vector autoregression approach and impulse response functions to capture both points in the context of the recent Brazilian experience.

\section{Empirical Methodology}

The analysis is based on a near-vector autoregression (near-VAR) model that captures the relationship emphasized in the foregoing discussion. ${ }^{7}$ The specific variables included in the near-VAR model are private capital inflows as a proportion of aggregate output (denoted $k y$ ), changes in the world nominal interest rate $\left(\Delta i^{*}\right)$, changes in the domestic nominal interest rate $(\Delta i)$, government spending as a proportion of aggregate output $(g y)$, changes in the expected depreciation rate $\left(\Delta \varepsilon^{e}\right)$, and changes in the real exchange rate $(\Delta q)$. The use of changes in domestic and foreign interest rates and the expected rate of depreciation is consistent with the view that levels of these variables affect the stock demand for assets, as, for instance, in Agénor (1997 and 1998). The focus on changes in the real exchange rate is mostly motivated by the assumption that, in line with the analytical models described in the previous section, it is the stock of net foreign assets, rather than the change in this stock (capital flows), that affects the trend (or equilibrium) value of the real exchange rate. ${ }^{8}$

\footnotetext{
${ }^{7}$ Our methodology is described in more detail in appendix A. See Hamilton (1994) for a general discussion of the VAR methodology.

${ }^{8}$ We also note that our focus is due to the fact that it would seem overambitious to try to
} 
The near-VAR model allows us to treat $\Delta i^{*}$ as a block exogenous variable in the system. This treatment is consistent with the idea that changes in world nominal interest rates $\left(\Delta i^{*}\right)$ are unlikely to be affected by domestic shocks in Brazil. The endogenous block of the near-VAR consists therefore of $k y, \Delta i, g y, \Delta \varepsilon^{e}$, and, $\Delta q$. To guarantee a symmetric effect in the long run of changes in the rates of return between domestic and foreign assets (adjusted for expected depreciation) on capital flows, we impose a restriction that the effect of $\Delta i$ must be equal in the long run to the effect of $\Delta i^{*}+\Delta \varepsilon^{e}$, with a negative sign. ${ }^{9}$

The near-VAR model was used to calculate variance decompositions and impulse response functions in a "generalized" VAR framework, as proposed by Koop, Pesaran, and Potter (1996). An attractive feature of this approach is that it does not suffer from the "compositional effect" inherent in standard VAR analysis. As is well known, variance decompositions and impulse response functions derived from standard VAR analysis, depend on the ordering of the variables used to obtain the orthogonal shocks. ${ }^{10}$ This dependence reflects the fact that changing the ordering changes the implicit linear combination of the VAR innovations used to obtain the orthogonal shock, that is, changing the ordering changes the "composition" of the orthogonal shock.

Generalized VAR analysis is based on rethinking what is to be "recovered" from the estimated VAR, or near-VAR, model (see appendix A for details). Consider impulse responses. Typically a VAR is subjected to an orthogonal shock, and the impulse responses trace out the dynamic response of the model to that shock. Note that implicitly these impulse responses compare the evolution of the model following the shock to a baseline model not subject

identify long-run equilibrium movements of the real exchange rate, given the short time span covered by the available data.

${ }^{9}$ Agénor and Hoffmaister (1998) impose this parity condition for all time periods by including in the VAR model the variable $\Delta$ idif $f \equiv \Delta i-\left(\Delta i^{*}+\Delta \varepsilon^{e}\right)$ that imposes the restriction that for each lag the parameter coefficients on $\Delta i^{*}$ and $\Delta \varepsilon^{e}$ are equal and of opposite sign to that of $\Delta i$. Here this restriction is imposed in the long run, that is, on the sum of the parameter coefficients of the lagged values of all these variables. Thus, the model allows short-run deviations from the symmetry condition.

${ }^{10}$ Analysts that conduct so-called "atheoretical" empirical investigations frequently note that their results are robust to the ordering used. However, robustness to different orderings does not guarantee that standard VAR analysis has succeeded in recovering economically meaningful shocks. See Keating (1996) for a full discussion of this issue. 
to the shock. Generalized impulse responses (GIRs) build upon this idea and propose to look instead at a "typical" historical shock. GIRs compare the "average" dynamic responses of the model given a "typical" historical shock and the history of the model, compared to the "average" baseline model not subject to the shock given the history of the model. Specifically, GIRs compare the conditional expectation of a variable in the model given an arbitrary current shock $v_{t}$ and history $\Omega$, to the conditional expectation of that variable given history:

$$
G I R\left(x_{t+k}, v_{t}, \Omega\right)=E\left[X_{t+k} \mid v_{t}, \Omega\right]-E\left[X_{t+k} \mid \Omega\right]
$$

It is important to note that because the GIR captures the historically observed information regarding shocks in the data, it does not intend to recover the responses to a "pure" world interest rate shock, that is, these historical shocks are not typically orthogonal. Likewise, the generalized variance decompositions (GVDs) measure does not intend to measure the percentage of the variance attributed to "pure" shocks, and hence would not typically add up to 100 percent.

\section{Estimation and Variance Decompositions}

Precise definitions of all the variables and the statistical adequacy of the near-VAR model are discussed in appendices B and C. We use two measures of the expected rate of depreciation of the nominal exchange rate: the first is based on actual, one-period ahead movements in the exchange rate, and the second is based on survey measures. In what follows, we will refer to the former as model 1 and the latter as model 2. Both versions of the model were estimated using monthly data over the period 1988:M6 through 1995:M9. The results presented in this paper are based on models with four lags; the lag selection is discussed in appendix C. In addition to seasonal dummies to control for seasonality, the near-VAR model included two dummy variables to control for the Real Plan (with a value of 1 from 1994:M7 onward) and for the "tequila" effect that affected Brazil during the first quarter of 1995. These dummies have very small impact on the empirical results described below, but are nonetheless statistically significant. 
Table 2 presents the GVDs for capital flows, $k y$, and changes in the real exchange rate, $\Delta q$, for both definitions of the expected rate of depreciation. The GVDs for ky suggest that its movements at short forecasting horizons are driven almost exclusively by the historical innovations in $k y$ itself. As the forecast horizon increases, the importance of historical shocks associated with $g y, \Delta i^{*}$ and $\Delta i$ increases. Interestingly, this effect shows up in the results obtained with both measures of the expected rate of depreciation. This is also true for the historical innovations associated with changes in the expected rate of depreciation, particularly for the measure based on actual movements of the exchange rate. Our results do not, therefore, corroborate the view that capital inflows to Brazil have been mainly driven by external (push) factors - in contrast to the evidence for other countries discussed, for instance, by Calvo, Leiderman, and Reinhart (1996), Corbo and Hernández (1996), or Chuhan, Claessens, and Mamingi (1998). ${ }^{11}$

The GVDs for changes in the real exchange rate suggest that its movements at short forecasting horizons are mostly associated with its own historical innovations in the real exchange rate itself. As the forecast horizon increases to six months, the historical innovations associated with changes in the world interest rate explain between $10 \%$ and $15 \%$ of the movements in $\Delta q$. At longer horizons, shocks to capital flows explain about $10 \%$ of these movements. Similar results were obtained for both domestic interest rates and government spending. Nonetheless, a significant portion of the movements in the real exchange rate remains associated with its own historical innovations in the medium term. ${ }^{12}$

\footnotetext{
${ }^{11}$ These results are virtually unchanged when the models are estimated as full VAR models. The main difference is that the share of the variance of capital flows associated with historical shocks to $\Delta i^{*}$ are a bit smaller - roughly 4\% and 9\% at a 24-month horizon, respectively, in models 1 and 2. The results in the paper are somewhat more sensitive to the number of lags used in estimating the near-VAR model. Using six lags, the share of the variance of capital flows related to historical shocks associated with $\Delta i^{*}$ increases to about $20 \%$ in model 1 at a 24-month horizon and are unchanged in model 2. In addition, the share of the variance of the real exchange rate associated with shocks to $\Delta i^{*}$ increases in model 2 to about 40\% at a 24month horizon and are unchanged in model 1. With higher lag lengths, both models tend to exhibit explosive behavior.

${ }^{12}$ Evidence in support of a larger effect of government spending shocks on the real exchange rate for Brazil is provided by Hoffmaister and Roldós (2001). Note, however, that we use higher frequency data than they do.
} 
Table 2a

Generalized variance decompositions: real exchange rate $(\Delta q)$

\begin{tabular}{|c|c|c|c|c|c|c|}
\hline \multirow{2}{*}{$\begin{array}{l}\text { Model/ } \\
\text { Horizon }\end{array}$} & \multicolumn{6}{|c|}{ Percentage of the variance associated with historical shocks to } \\
\hline & $\Delta i *$ & $\Delta i$ & $\Delta E[e]$ & $\Delta q$ & $k y$ & $g y$ \\
\hline \multicolumn{7}{|l|}{ Model 1} \\
\hline 1 & 8.6 & 6.7 & 0.1 & 100.0 & 0.0 & 0.0 \\
\hline 3 & 9.2 & 7.0 & 1.0 & 93.1 & 2.4 & 0.2 \\
\hline 6 & 10.7 & 7.3 & 1.4 & 81.1 & 8.8 & 6.9 \\
\hline 12 & 11.5 & 7.1 & 1.6 & 79.2 & 9.9 & 7.2 \\
\hline 24 & 11.5 & 7.1 & 1.6 & 79.1 & 9.9 & 7.2 \\
\hline \multicolumn{7}{|l|}{ Model 2} \\
\hline 1 & 11.3 & 7.2 & 0.3 & 100.0 & 3.0 & 0.2 \\
\hline 3 & 12.1 & 8.8 & 4.5 & 89.4 & 3.1 & 1.4 \\
\hline 6 & 14.0 & 8.3 & 5.2 & 78.1 & 6.3 & 6.8 \\
\hline 12 & 15.1 & 8.0 & 6.7 & 71.9 & 7.9 & 7.9 \\
\hline 24 & 15.0 & 8.0 & 7.4 & 69.5 & 8.8 & 8.0 \\
\hline
\end{tabular}

Note: Based on the near-VAR models (with four lags) discussed in the text. The variables in the models are: the world interest rate, $\Delta i *$; the domestic interest rate, $\Delta i$; the expected rate of depreciation, $\Delta E[e]$; real depreciation, $\Delta q$; capital flows, $k y$; and government spending, $g y . E[e]$ is measured using actual nominal exchange rate data (model 1) and using survey data (model 2). All variables are expressed in changes, except $k y$ and $g y$ that are expressed as shares of output.

Table 2b

Generalized variance decompositions: capital flows $(k y)$

\begin{tabular}{crrrrrr}
\hline Model/ & \multicolumn{6}{c}{ Percentage of the variance associated with historical shocks to } \\
Horizon & $\Delta i *$ & $\Delta i$ & $\Delta E[e]$ & $\Delta q$ & $k y$ & \multicolumn{1}{c}{$g y$} \\
\hline Model 1 & & & & & & \\
1 & 1.2 & 9.9 & 4.8 & 0.0 & 100.0 & 13.5 \\
3 & 1.9 & 15.2 & 21.5 & 0.8 & 79.8 & 8.7 \\
6 & 3.0 & 14.5 & 21.3 & 0.7 & 69.0 & 15.3 \\
12 & 4.4 & 13.1 & 20.9 & 1.8 & 62.5 & 17.9 \\
24 & 6.0 & 12.6 & 20.5 & 2.2 & 60.8 & 17.9 \\
Model 2 & & & & & & \\
1 & 1.5 & 0.0 & 2.2 & 3.0 & 100.0 & 4.7 \\
3 & 3.0 & 6.2 & 4.7 & 2.3 & 75.4 & 8.8 \\
6 & 5.2 & 5.0 & 8.9 & 1.6 & 52.2 & 19.3 \\
12 & 10.8 & 5.1 & 8.9 & 4.6 & 44.7 & 21.9 \\
24 & 11.6 & 5.0 & 9.5 & 4.8 & 44.9 & 21.0 \\
\hline
\end{tabular}

Note: Based on the near-VAR models (with four lags) discussed in the text. The variables in the models are: the world interest rate, $\Delta i *$; the domestic interest rate, $\Delta i$; the expected rate of depreciation, $\Delta E[e]$; real depreciation, $\Delta q$; capital flows, $k y$; and government spending, $g y . E[e]$ is measured using actual nominal exchange rate data (model 1) and using survey data (model 2). All variables are expressed in changes, except $k y$ and $g y$ that are expressed as shares of output. 


\section{Shock to Foreign Interest Rates}

Figures 2 and 3 contain the GIR for the variables in the near-VAR, for both measures of expected depreciation, associated with a shock to foreign nominal interest rates. One-standard error bands for each variable are also shown. ${ }^{13}$

With both measures of expected depreciation, a temporary (one-period only) increase in $\Delta i^{*}$ (that is, a permanent increase in $i^{*}$ ) leads on impact to a significant fall in domestic interest rates and a fall in the expected rate of appreciation of the nominal exchange rate. ${ }^{14}$ The fall in $\Delta \varepsilon^{e}$ is such that the interest rate differential (the difference between the domestic interest rate and the sum of the foreign interest rate and the expected rate of nominal depreciation) falls on impact, leading to a capital inflow; the figures show that the impact effects on $\Delta i, \Delta i^{*}$, and $\Delta \varepsilon^{e}$ are about $-0.01,0.01$, and -0.04 , respectively. A similar movement occurs when using survey data to measure expectations. In subsequent months, domestic interest rates fluctuate significantly whereas capital inflows become positive. The real exchange rate starts depreciating after about four months. The government spending-GDP ratio falls on impact, increases between the second and fourth months following the shock, and falls again subsequently. ${ }^{15}$

These results can be interpreted within the context of the models developed by Agénor (1998) and Kollmann (1997). In Agénor's model, for instance, the rise in the foreign interest rate (as indicated earlier) generates

\footnotetext{
${ }^{13}$ In both figures the dotted lines for the GIRs show one standard error band in each direction and are based on 1 thousand Monte Carlo replications. In each replication we sample the near-VAR coefficients and the covariance matrix from their posterior distribution. From these replications we calculate the square root of the mean squared deviation from the impulse response in each direction. By construction these bands contain the impulse response function but are not necessarily symmetric. See Kloek and VanDijk (1978) for details of the posterior distributions.

${ }^{14}$ Throughout this discussion a "significant" response for a given month following the shock means that the interval defined by the error bands does not contain the value zero. In this sense, the error bands are used in a manner that is analogous to "t-statistics." Note that in the figures, the immediate impact of the change in $\Delta i^{*}$ is significant in this sense for all the variables in the model. For ease of exposition, when we refer to the significance over several periods, it should be understood that each individual month in that period is significant. For instance, in model 1 the response of $\Delta q$ is significant for a quarter, meaning that it is significant for each month in that quarter.

${ }^{15}$ As before, the results are virtually unchanged when the models are estimated as full VAR models. When the models are estimated with six lags, the impact effects are unchanged but the dynamics increases in complexity and becomes very difficult to interpret.
} 
Figure 2

Model 1: shock to foreign interest rate

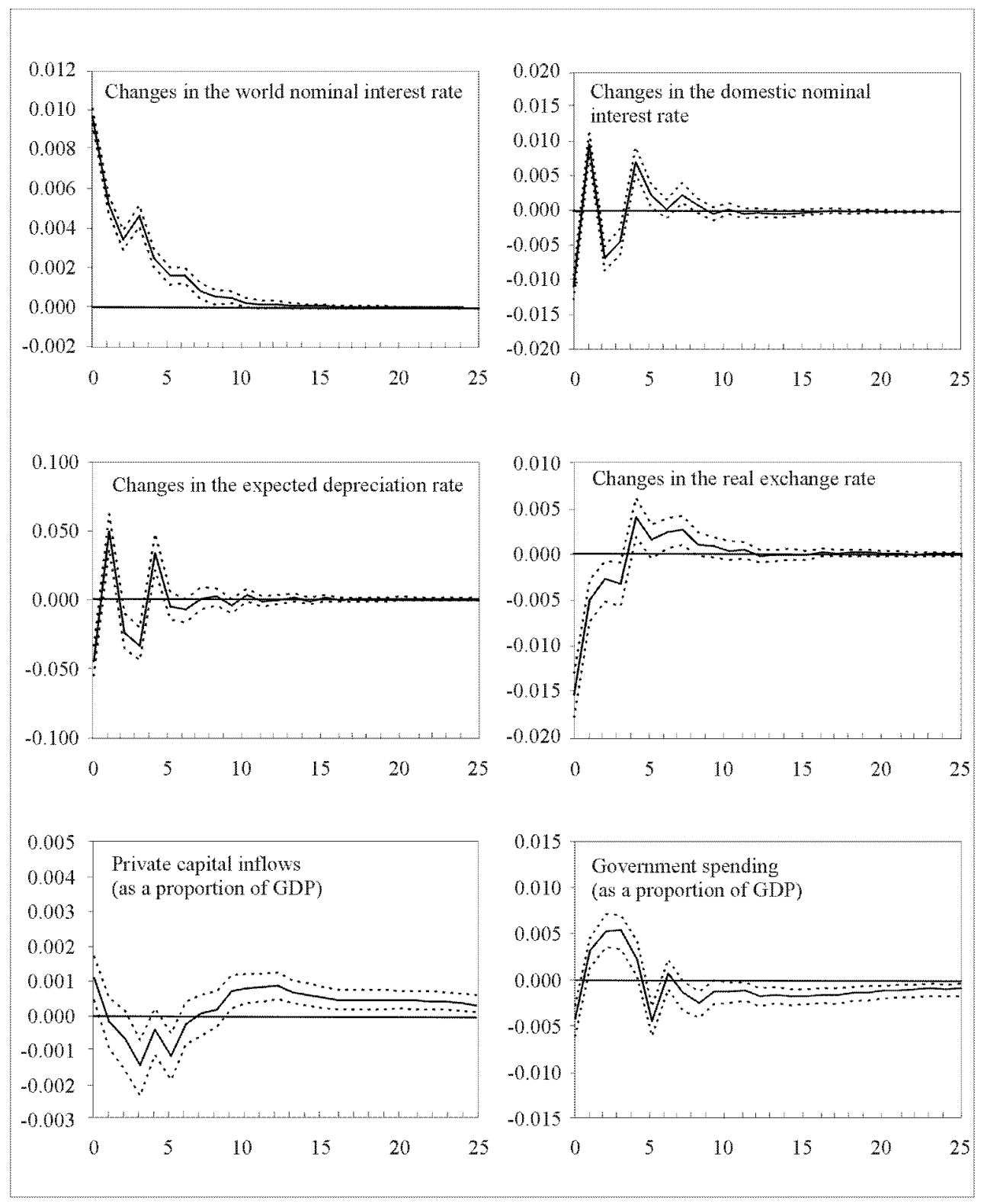


Figure 3

Model 2: shock to foreign interest rate

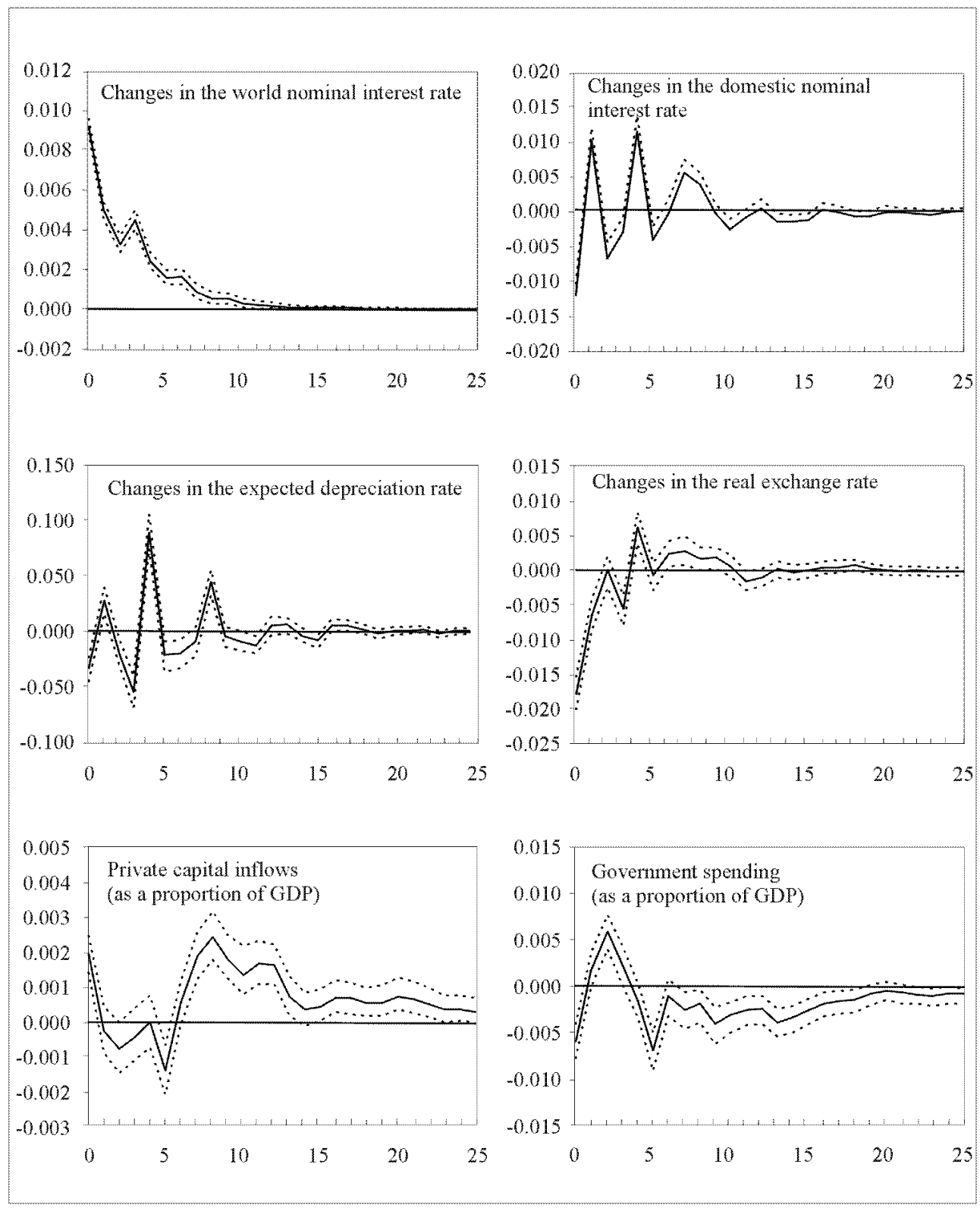


both wealth and intertemporal substitution effects. If private agents are net creditors, these effects will tend to offset each other. If the degree of intertemporal substitution is small (as suggested by the evidence on Brazil obtained, for instance, by Reinhart and Végh, 1995), the net effect will be positive, and private consumption will increase. The increase in private expenditure will put upward pressure on the relative price of nontrable goods. And although government spending falls, the net effect will be an appreciation of the real exchange rate. The increase in private consumption will tend to put upward pressure on domestic interest rates; however, at the same time, the capital inflow leads to an increase in the money supply (in the absence of full sterilization), which, together with the fall in the government spending-output ratio, is large enough to ensure that domestic interest rates fall on impact. The swings observed in movements of domestic interest rates in subsequent periods may be associated with the observed fluctuations in capital flows and exchange rate expectations.

\section{Summary and Conclusions}

The purpose of this paper has been to examine the links between external shocks, capital inflows, and the real exchange rate in Brazil. The first part provided a brief analytical background, which emphasized the ambiguity in the effect of shocks to world interest rates on the real exchange rate in the short run. The second part described our methodology and the model used for the empirical analysis, namely a near-vector autoregression model linking capital inflows, domestic and foreign interest rates, expected changes in the nominal rate of depreciation, the government spending-output ratio, and changes in the real exchange rate.

The model was estimated using monthly data for the period 1988-95. Variance decompositions suggest that, in the short run, fluctuations in capital inflows are driven almost exclusively by the historical innovations in capital inflows themselves, at short forecasting horizons. In the longer run, shocks to the world interest rate play a somewhat larger role but continue to account for only a fraction of fluctuations in capital inflows. Fluctuations in the real exchange rate are also associated mostly with the historical innovations in the real exchange rate itself at short forecasting horizons, and, to some limited extent, with world interest rate shocks at longer horizons. The analysis of impulse response functions indicated that a reduction in foreign interest rates 
leads to impact to capital inflow (as a result mostly of a relatively large fall in the expected rate of depreciation), and an appreciation of the real exchange rate.

We caution, however, that care is needed when interpreting these results as the high frequency data used, in particular capital inflows and government spending, are not without caveats. High frequency data for short-term credit lines are not available and thus our measure of net private capital inflows is not as comprehensive as we would have liked. In principle, we could have incorporated these flows by interpolating the annual short-term credit. We are, however, apprehensive about using mechanical methods because little high frequency information could be gained by "smoothing" this highly volatile series, and using a related series (the world interest rate, for instance) for interpolation introduces information favoring a particular hypothesis (in this case, changes in world interest rates). Regarding government spending data, those available to us refer to expenditure on a cash basis and cover outlays by the federal government only. The problems of mismatching the moment when the expenditures are accrued and the moment when the expenditures are recorded become more evident with higher frequency data. ${ }^{16}$ While it is impossible to know with certainty how these data limitations affect our results, we speculate that, had high frequency data on short-time credit lines been available, the impact of world interest rates would have been even more pronounced. This is because a decline in world interest rates, by reducing the cost of short-term borrowing, would tend to reinforce net capital flows to Brazil. It is also possible that the role of world interest rates in explaining capital inflows in the medium and long term would be reinforced and perhaps extended to the short run as well.

\section{References}

Agénor, Pierre-Richard. Capital-market imperfections and the macroeconomic dynamics of small indebted economies. (Princeton Study in International Finance, 82.)

. Capital inflows, external shocks, and the real exchange rate. Journal of International Money and Finance, 1\%:713-40, Oct. 1998.

\footnotetext{
${ }^{16}$ Moreover, the process of decentralization of fiscal expenditures, which has intensified in recent years, introduces a systematic and increasing understatement of expenditures that tends to obscure the actual impact that government expenditures have on the economy.
} 
\& Hoffmaister, Alexander W. Capital inflows and the real exchange rate: analytical framework and econometric evidence. In: Glick, Reuven (ed.). Managing capital flows and exchange rates: lessons from the Pacific Basin, Cambridge, Cambridge University Press, 1998.

Bernanke, Ben. Alternative explanations of the money-income correlation. 1986. p. 49-100. (Carnegie-Rochester Conference Series on Public Policy, 25.)

\& Blinder, Allan S. The federal funds rate and the channels of monetary transmission. American Economic Review, 82:901-21, Sept. 1992.

Blanchard, Olivier J. \& Quah, Danny. The dynamic effects of aggregate demand and supply disturbances. American Economic Review, 79:655-73, Sept. 1989.

Calvo, Guillermo A.; Leiderman, Leonardo \& Reinhart, Carmen M. Inflows of capital to developing countries in the 1990s: causes and effects. Journal of Economic Perspectives, 10:123-39, Spring 1996.

Cardoso, Eliana. Brazil's macroeconomic policies and capital flows in the 1990s. International Monetary Fund, 1997. unpublished.

\& Goldfajn, Ilan. Capital flows to Brazil: the endogeneity of capital controls. IMF Staff Papers, 45:161-202, Mar. 1998.

Chuhan, Punam; Claessens, Sitjn \& Mamingi, Nandu. Equity and bond flows to Latin America and Asia: the role of global and country factors. Journal of Development Economics, 55:439-63, Apr. 1998.

Cooley, Thomas A. \& LeRoy, Stephen F. Atheoretical macroeconometrics: a critique. Journal of Monetary Economics, 16:283-308, Nov. 1985.

Corbo, Vittorio \& Hernández, Leonardo. Macroeconomic adjustment to capital inflows: lessons from recent Latin American and East Asian experience. World Bank Research Observer, 11:61-85, Feb. 1996.

Dhrymes, Phoebus J. Introductory econometrics. New York, Springer-Verlag, 1978.

Dickey, David A. \& Rossana, Robert J. Cointegrated time series: a guide to estimation and hypothesis testing. Oxford Bulletin of Economics and Statistics, 56:325-53, Aug. 1994. 
Doan, Thomas A. RATS, user's manual version 4. Evanston, Estima, 1992. ch. 8 .

Faruqee, Hamid. Long-run determinants of the real exchange rate: a stockflow perspective. IMF Staff Papers, 42:80-107, Mar. 1995.

Faust, J. \& Leeper, Eric M. When do long-run identifying restrictions give reliable results? Board of Governors of the Federal Reserve System, 1994. (International Finance Discussion Paper, 462.)

Fernández-Arias, Eduardo. The new wave of capital inflows: push or pull? Journal of Development Economics, 48:389-418, Mar. 1996.

Frankel, Jeffrey A. \& Okongwu, Chudozie. Liberalized portfolio capital inflows in emerging markets: sterilization, expectations, and the incompleteness of interest rate convergence. International Journal of Finance and Economics, (1):1-24, Jan. 1996.

Garcia, Márcio G. \& Barcinski, Alexandre. Capital flows to Brazil in the nineties: macroeconomic aspects and the effectiveness of capital controls. PUC, 1996. unpublished.

Hamilton, James D. Time series analysis. Princeton, Princeton University Press, 1994.

Hoffmaister, Alexander W. \& Roldós, Jorge E. The sources of macroeconomic fluctuations in developing countries: Brazil and Korea. Journal of Macroeconomics, 23:213-39, Spring 2001.

Keating, John W. Structural information in recursive VAR orderings. Journal of Economic Dynamics and Control, 20:1.557-80, Sept. 1996.

Kloek, Tuen \& Van Dijk, Herman K. Bayesian estimates of equation system parameters: an application of integration by Monte Carlo. Econometrica, 46:1-20, Jan. 1978.

Kollman, Robert. The exchange rate in a dynamic-optimizing current account model with nominal rigidities: a quantitative investigation. International Monetary Fund, 1997. (Working Paper, 97/7.)

Koop, Gary; Pesaran, M. Hashem \& Potter, Simon N. Impulse response analysis in nonlinear multivariate models. Journal of Econometrics, 74:119-47, Mar. 1996. 
Lippi, Marco \& Reichlin, Lucrezia. The dynamic effects of aggregate demand and supply disturbances: a comment. American Economic Review, 83:644-52, June 1993.

McKinnon, James. Critical values for cointegration tests. In: Engle, Robert \& Granger, Clive W. Long-run economic relationships: readings in cointegration. Oxford, Oxford University Press, 1991.

Pesaran, M. Hashem \& Shin, Yongcheol. Generalized impulse response analysis in linear multivariate models. Cambridge University, 1997. unpublished.

Reinhart, Carmen M. \& Végh, Carlos A. Nominal interest rates, consumption booms, and lack of credibility. Journal of Development Economics, 46:357-78, Apr. 1995.

Shapiro, M. D. \& Watson, Mark W. Sources of business cycle fluctuations. NBER Macroeconomics Annual 198\%. Cambridge, MIT Press, 1988.

\section{Appendix A}

\section{Generalized VAR analysis}

Our empirical analysis uses the so-called generalized VAR analysis proposed by Koop, Pesaran and Potter (1996). This approach has the distinct advantage of identifying unique (order invariant) impulse responses and variance decompositions. To describe this methodology, we begin with a brief description of standard VAR analysis.

Consider the following VAR model:

$$
C(L) y_{t}=\mu_{t}
$$

where $y_{t}$ is a vector containing the $k$ variables in the model, $C(L)$ is a lag polynomial matrix with the VAR coefficients, and the vector $\mu_{t}$ contains the VAR innovations with $E\left[\mu_{t}\right]=0$ and $E\left[\mu_{t} \mu_{t}^{\prime}\right]=\Omega$.

Direct examination of the VAR innovations can be misleading because these innovations are contemporaneously correlated. In other words, examining the effects of a single component of $\mu_{t}$ while keeping the other components of $\mu_{t}$ constant is not consistent with the historical information summarized in 
$\Omega$ and thus would be misleading. That is, the VAR innovations do not embody the historical correlations of the shocks summarized by the covariance matrix, $\Omega$.

Sims (1980) proposed examining instead a transformed model that is obtained by pre-multiplying equation $(\mathrm{A} 1)$ by a square matrix $R^{-1}$ :

$$
R^{-1} C(L) y_{t}=R^{-1} \mu_{t},
$$

which is such that the transformed innovations on the right hand side are orthogonal; that is, letting $\varepsilon_{t}=R^{-1} \mu_{t}$, the transformation is such that $E\left[\varepsilon_{t} \varepsilon_{t}^{\prime}\right]=I{ }^{17}$ Direct examination of $\varepsilon_{t}$ would be, at least in principle, meaningful. Note that the orthogonalization of $\mu_{t}$ requires that $R^{-1} \Omega R^{-1 \prime}=I$ (or simply $\Omega=R R^{\prime}$ ), which led Sims to suggest that the matrix $R$ be the (lower) Choleski decomposition of $\Omega$. Since the Choleski decomposition yields a (lower) triangular matrix, it is clear that VAR analysis stemming from the Choleski decomposition of $\Omega$ describes a recursive system. Part of the uneasiness in the profession regarding this orthogonalization is associated with the fact that few economic models naturally lend themselves to a recursive form specification. Moreover, since the Choleski decomposition varies with the ordering chosen, VAR analysis along these lines does not lead to a unique set of results. ${ }^{18}$

Assuming that the system described by equation (A2) is invertible, the impulse response function for the orthogonal shock $\varepsilon_{t}$ is obtained by solving this system for $y_{t}$ :

$$
y_{t}=C(L)^{-1} R \varepsilon_{t} .
$$

Typically standard VAR analysis presents the impulse responses for an explicit ordering chosen by recourse to economic judgement, and some effort is made to address the reader's natural concern regarding the robustness of the results, mostly by discussing results for alternative orderings. However, analysis of all possible alternative orderings is only feasible for VAR systems involving a relatively small number of variables. Moreover, even with small

\footnotetext{
${ }^{17}$ Note that, for simplicity of notation, we have implicitly assumed unit variances for the transformed innovations. Since the structural innovations are contemporaneously uncorrelated, this amounts to choosing the scale of the innovations and has no bearing on the subsequent discussion.

${ }^{18}$ For a comprehensive treatment of standard VAR analysis, see Hamilton (1994).
} 
systems, results associated with alternative orderings are not always devoid of ambiguities.

The variance decomposition of $y_{t}$ is obtained by splitting the mean square forecasting error (MSFE) into the portions attributed to each shock. Consider the expression for $y_{t+s}$, from equation (A3):

$$
\begin{aligned}
y_{t+s} & =C(L)^{-1} R \varepsilon_{t+s} \\
& =A_{0} \varepsilon_{t+s}+A_{1} \varepsilon_{t+s-1}+A_{2} \varepsilon_{t+s-2}+\ldots+A_{s} \varepsilon_{t}+A_{s-1} \varepsilon_{t-1}+\ldots,
\end{aligned}
$$

that implicitly defines $A(L)=C(L)^{-1} R$. The (mean) forecast of $y_{t+s}$ in period $t$ is then:

$$
y_{t+s \mid t}=A_{s} \varepsilon_{t}+A_{s+1} \varepsilon_{t-1}+\ldots,
$$

where the expected values for $\varepsilon_{t+s}$ for $s>0$ are equal to zero, that is, equal to their expected value in period $t$. From equations (A4) and (A5) it is clear that the forecasting error in period $t$ is then:

$$
y_{t+s}-y_{t+s \mid t}=A_{0} \varepsilon_{t+s}+A_{1} \varepsilon_{t+s-1}+A_{2} \varepsilon_{t+s-2}+\ldots+A_{s-1} \varepsilon_{t+1} .
$$

Note that equation (A6) expresses the forecasting error of $y_{t+s}$ using the first $s$ terms in $A(L)$.

The MSFE is obtained by taking the expectation of $\left[\left(y_{t+s}-y_{t+s \mid t}\right)\left(y_{t+s}-\right.\right.$ $\left.\left.y_{t+s \mid t}\right)^{\prime}\right] .{ }^{19}$ To split the MSFE into the portion associated with each of the $k$ shocks in $\varepsilon_{n}$, with $n=t+1, \ldots, t+s$, it is convenient to partition the square matrices $A_{i}$ into $k$ columns; let $A_{i j}$ denote the $j t h$ column of the matrix $A_{i}$, and $e_{j}$ the $j t h$ shock in $\varepsilon_{n}$, so that

$$
A_{i} \varepsilon=A_{i 1} e_{1}+A_{i 2} e_{2}+\ldots+A_{i k} e_{k}
$$

where, for notational convenience, the time subscript to $\varepsilon$ has been omitted.

The MSFE can be expressed as the sum of $k$ components, each associated with individual elements of $\varepsilon$, as follows: ${ }^{20}$

$$
\operatorname{MSFE}\left(y_{t+s}\right)=E\left[\sum_{j=1}^{k}\left\{e_{j} e_{j}^{\prime}\left(A_{0 j} A_{0 j}^{\prime}+A_{1 j} A_{1 j}^{\prime}+\ldots+A_{s-1 j} A_{s-1 j}^{\prime}\right)\right\}\right] .
$$

\footnotetext{
${ }^{19}$ Note that the MSFE for each of the $k$ variables in $y_{t}$ are the diagonal elements of the expectation of the outer product.

${ }^{20}$ Since $\varepsilon_{t}$ is assumed to be i.i.d., the time dimension has been dropped in equation (A7).
} 
Note that because $E\left[\varepsilon \varepsilon^{\prime}\right]=I$, that is, the variance of each shock $e_{j}$ is unity and these shocks are orthogonal, the expectation term on the left hand side of equation (A7) contains no covariance terms. Thus, the contribution of shock $j$ to the forecasting error of $y_{t+s}$ will equal $\left(A_{0 j} A_{0 j}^{\prime}+A_{1 j} A_{1 j}^{\prime}+\ldots+A_{s-1 j} A_{s-1 j}^{\prime}\right)$, suitably scaled by $\operatorname{MSFE}\left(y_{t+s}\right)$. It should be clear that since $A(L)$ depends on the ordering used to calculate the Choleski decomposition, the variance decomposition will vary with the ordering, as indicated earlier.

Cooley and LeRoy (1985), in the context of a bivariate system, and Bernanke and Blinder (1992), in a more general setting, argue that the identification strategy described earlier will recover the pure structural innovations only when the variable of interest is predetermined and is placed first in the ordering. ${ }^{21}$ More recently, Keating (1996) has discussed the general conditions needed for Choleski decompositions to be informative of the underlying structural innovations. Specifically, he has shown that the "appropriate" Choleski ordering will recover the structural innovations provided that the system is block recursive. $^{22}$ As noted before, our study follows an entirely different strategy based on the so-called generalized VAR analysis proposed by Koop, Pesaran, and Potter (1996).

Generalized VAR analysis is based on reconsidering what impulse response functions and variance decompositions are meant to uncover. Standard VAR techniques require that the analyst take a stand on how to recover and/or identify structural innovations, through the choice of the square matrix $R$. Koop, Pesaran and Potter (1996) argue that the whole notion should be re-examined, and proposed to change the focus from the "pure" structural shocks that are identified by orthogonalizing VAR innovations, to an understanding of what a typical historical innovation tells us regarding the dynamics of the model. These historical innovations are not necessarily orthogonal, but, contrary to VAR innovations, embody the information regarding the contemporaneous correlation of these innovations.

\footnotetext{
${ }^{21}$ These issues contributed to the development of alternative identification strategies of structural innovations. These alternative strategies impose more restrictions based on economic theory (or economic structure) on the identification process. The so-called "structural" VAR approaches, beginning with Bernanke (1986), Blanchard and Quah (1989), and Shapiro and Watson (1988), have also come under attack by Faust and Leeper (1994) and Lippi and Reichlin (1993).

${ }^{22}$ A block recursive system or a "partially recursive" structure is one where the structural equations in one block have a recursive ordering in that block and the contemporaneous covariance matrix for structural shocks is diagonal. See Keating (1996) for a complete discussion.
} 
Consider again equation (A1) in moving average form:

$$
y_{t}=C(L)^{-1} \mu_{t}
$$

and assume further that $\mu_{t}$ is distributed multivariate normal, that is, $N(0, \Omega)$. Note that this implies that $y_{t}$ is also multivariate normal with zero mean and covariance matrix $C(L)^{-1} \Omega C(L)^{-1 \prime} \cdot{ }^{23}$ Rather than orthogonalizing the VAR innovations, generalized impulse responses (GIR) analysis considers the conditional expectation of $y_{t}$ given a specific shock to $\mu_{t}$.

The "average" effect on $y_{t}$ of a historical shock of, say, $\mu_{i t}$, the $i$ th component of $\mu_{t}$, can be obtained by taking the expectation of equation (A8) conditional on the shock $\mu_{i t}=v$,

$$
G I R\left(Y_{t}, \mu_{i t}=v\right)=E\left[Y_{t} \mid \mu_{i t}=v, \Omega\right]=C(L)^{-1} E\left[\mu \mid \mu_{i t}=v, \Omega\right]
$$

and given the properties of the multivariate normal distribution: ${ }^{24}$

$$
G I R\left(Y_{t}, \mu_{i t}=v\right)=C(L)^{-1} \Omega_{i} \sigma_{i i}^{-1} v
$$

where $\Omega_{i}$ is the $i$ th column of $\Omega$. Although $v$ could be any value, it seems appropriate to set it equal to its historical value: the standard error of the $i$ th shock, $\sigma_{i i}^{1 / 2}$. This choice for the value of $v$ corresponds to a unit shock of the historical shock. ${ }^{25}$

In general, the GIR in equation (A9) will differ from the standard impulse responses noted in equation (A3). But since the first column of the Choleski decomposition of $\Omega$ has the form

$$
R_{1}=\left[\sigma_{11}^{-1 / 2}, \quad \sigma_{21} \sigma_{11}^{-1 / 2}, \quad \sigma_{31} \sigma_{11}^{-1 / 2}, \ldots, \sigma_{k 1} \sigma_{11}^{-1 / 2}\right]^{\prime}
$$

the GIR for the $i$ th shock will be numerically equivalent to the impulse response function obtained using the Choleski decomposition when the $i$ th variable is put first in the ordering. ${ }^{26}$ Also note that they will be numerically

\footnotetext{
${ }^{23}$ In equation (A8), all non-zero deterministic components have been implicitly substracted from $y_{t}$.

${ }^{24}$ See Dhrymes (1978:362-7) for the explicit derivation of the conditional expectation of a multivariate normal.

${ }^{25}$ This methodology is extended to more general types of shocks and to nonlinear models in Koop, Pesaran and Potter (1996), and to cointegrated systems by Pesaran and Shin (1997).

${ }^{26}$ For an explicit derivation of the Choleski decomposition shown in (A10), see Hamilton (1994:87-92).
} 
equivalent when $\Omega$ is diagonal, that is, when the system is subject to shocks that are independent.

The generalized variance decomposition (GVD) can be derived following a procedure similar to that discussed earlier. Namely, using the expression for $y_{t+s}$ and $y_{t+s \mid t}$ from equation (A8), the forecasting error can be expressed as:

$$
y_{t+s}-y_{t+s \mid t}=C_{0}^{-1} \mu_{t+s}+C_{1}^{-1} \mu_{t+s-1}+C_{2}^{-1} \varepsilon_{t+s-2}+\ldots+C_{s}^{-1} \mu_{t+1},
$$

where $C_{0}=I$.

To discuss the contribution of each shock, it is again convenient to partition the square matrices $C_{j}^{-1}$ into $k$ column vectors, such that $C_{j}^{-1}=$ $\left[C_{j 1}^{-1}, C_{j 2}^{-1}, \ldots, C_{j k}^{-1}\right]$, and denoting the $j$ th element of $\mu$ by $\mu_{j}$, then:

$$
y_{t+s}-y_{t+s \mid t}=\sum_{j=1}^{k}\left\{\mu_{j}\left(C_{j 0}^{-1}+C_{j 1}^{-1}+C_{j 2}^{-1}+\ldots+C_{j s}^{-1}\right)\right\} .
$$

Recall that the VAR innovation $\mu_{j}$ does not embody the historical correlations of the shocks as summarized by $\Omega$, so that using directly equation (A11) to calculate variance decompositions would be misleading. GVD proposes to look instead at the average portion of MSFE associated with each historical shock contained in $\mu$, conditional on the value of the shock equal to its standard error. Assuming as before that $\mu$ is multivariate normal,

$$
E\left[y_{t+s}-y_{t+s \mid t}\right]=\sum_{j=1}^{k}\left\{\Omega_{j} \sigma_{j j}^{-1 / 2}\left(C_{j 0}^{-1}+C_{j 1}^{-1}+C_{j 2}^{-1}+\ldots+C_{j s}^{-1}\right)\right\}
$$

This expression (squared) can be used to calculate the portion of the variance associated with each of the historical shocks suitably scaled by the $\operatorname{MSFE}\left(y_{t+s}\right)$. Note that although these historical shocks contain the information in $\Omega$, they are not typically orthogonal. Thus, "squared values" of equation (A12) will not add up to the $\operatorname{MSFE}\left(y_{t+s}\right)$, so the typical GVD will not add up to $100 \%$ unless the historical shocks are orthogonal. Also, note that the GVD for $y_{t+s}$ for the $j$ th shock will be numerically equivalent to the Choleski variance decomposition when the $j$ th variable is first in the ordering. 


\section{Appendix B}

\section{Data sources}

The data used in this paper are at a monthly frequency and cover the period 1988:M1 to 1995:M10. The variables are measured as follows.

$q$ is the log of the real exchange rate. The raw series corresponds to the real effective exchange rate, obtained from the IMF's International financial statistics (IFS).

$k y$ is the ratio of net private capital inflows to nominal GDP. The data on net capital inflows were provided by the Brazilian authorities and comprise net direct investment, net portfolio investment (equity and debt securities), and net private loans (intercompany loans, commercial paper, bonds, notes, and bank loans). It excludes reinvested profits and short-term credit lines. The former was excluded on economic grounds as these are typically not considered to be capital inflows and are small (roughly $15 \%$ of total net private capital inflows). The latter was excluded due to data limitations as this information is available on an annual basis. Despite the size of these credit lines reaching upwards of US $\$ 17$ billion in 1995, no mechanical interpolation of the annual data was attempted as the resulting (smoothed) interpolated series is unlikely to reflect the true high frequency magnitude of short-term credit lines. GDP at current prices was also provided by the Brazilian authorities.

$i$ is the overnight interest rate in Brazil (at a monthly rate), obtained from the Brazilian authorities.

$i^{*}$ is the US Treasury bill rate (at a monthly rate), obtained from the IMF (IFS line 60c).

$\varepsilon^{e}$ is the expected rate of depreciation of the nominal exchange rate, defined in two ways. First, as $\varepsilon^{e}=\ln \left(E_{+1} / E\right)$, where $E$ is the period average spot exchange rate of one US dollar measured in $E$ units of reales (IFS line ae). This measure is thus based on realized exchange rate values. Second, we used a direct expectations measure, derived from the monthly survey of some major participants in international financial markets conducted by the Currency Forecasters' Digest. ${ }^{27}$

\footnotetext{
${ }^{27}$ The Currency Forecasters' Digest (which is now the Financial Times Currency Forecasters) publishes currency forecasts (as well as indicators of forecasting risks) received from multinational companies, commercial and investment banks, and companies providing forecasting services. The data we use are those related to the "consensus" forecast.
} 
$g y$ is the ratio of total government expenditure at current prices on nominal GDP. Government spending was also provided by the Brazilian authorities.

\section{Appendix C}

\section{Near-VAR tests}

To determine the number of lags to include in the near-VAR model, we started by calculating standard lag-length tests, that is, Akaike's information criterion (AIC) and Hannan-Quinn (HQ). These tests compare the cost of increasing the lag length (reduced degrees of freedom) to the benefit (increased information extracted from the data). To deal with seasonality, the deterministic part of the near-VAR model includes a full set of seasonal dummies.

Using a maximum lag length of six, these test statistics suggested that only two lags were necessary. A priori these test results do not appear to be reasonable, even in light of the fact that seasonal dummies help to pick up seasonal information. Moreover, judging from Ljung-Box $Q$-statistics the residuals from the near-VAR model with two lags were not white noise. We thus opted to override the lag length tests and increase the lag length until the residuals from the VAR model were white noise. We found that four or five lags were needed to "whiten" the residuals, and thus, to conserve degrees of freedom, we used four lags to obtain the empirical results discussed in this paper. Robustness of the results to higher lags are noted in the paper.

Conditional on four lags, we tested the appropriateness of the near-VAR model where $\Delta i^{*}$ is block exogenous. This was done using the multivariate generalization of the Granger causality test proposed by Doan (1992). This is a multivariate likelihood ratio test that compares the likelihood under the null of the near-VAR to that under the alternative of a full VAR. The resulting test statistic is distributed $\chi^{2}$ with degrees of freedom equal to the number of variables excluded from the VAR under the null. In our model, the near-VAR specification excludes four lags of five variables in one equation for a total of 20 degrees of freedom. The test statistic $\left(\chi^{2}=24.4\right)$ does not reject the null hypothesis of the near-VAR specification at conventional significance levels. 